\title{
Analisis Dimensi Budaya Keselamatan Pasien Oleh Petugas Kesehatan di RSUD dr Rasidin Padang Tahun 2018
}

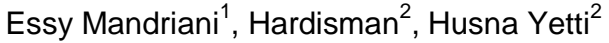

\begin{abstract}
Abstrak
Keselamatan rumah sakit saat ini telah menjadi isu global. Terdapat lima komponen penting yang terkait dengan keselamatan rumah sakit yang salah satunya adalah keselamatan pasien. Keselamatan pasien dipengaruhi oleh bagaimana budaya individu dan sistem yang berjalan di dalam organisasi tersebut. Tujuan penelitian ini adalah menganalisis budaya keselamatan pasien di RSUD dr Rasidin Padang tahun 2018. Penelitian ini menggunakan desain penelitian mix method. Pendekatan kuantitatif menggunakan kuesioner AHRQ (Agency Health Research and Quality) tahun 2004 sedangkan penelitian kualitatif menggunakan pendekatan instrumental case study. Subjek penelitian adalah seluruh petugas kesehatan yang berhubungan langsung dengan pasien sebanyak 250 sampel. Data kualitatif didapatkan melalui indepth interview kepada informan untuk menggali secara mendalam hambatan penerapan budaya keselamatan pasien. Hasil penelitian menunjukkan dimensi yang paling tinggi respon positifnya adalah dimensi supervisi (78\%) dan dimensi yang paling rendah adalah frekuensi pelaporan (31\%). Hambatan yang ditemui dalam pelaksanaan budaya keselamatan pasien adalah perilaku dari petugas kesehatan dan dukungan dari manajemen yang belum maksimal. Rekomendasi yang diberikan adalah pembentukan tim KPRS, edukasi dan monitoring evaluasi.
\end{abstract}

Kata Kunci: budaya keselamatan pasien, rumah sakit, petugas kesehatan

\begin{abstract}
Safety hospital has became a global issue. There are five important component related to safety in hospitals patient safety is one of them. Patient safety was influenced by individual culture and systems running within the organization. The objective of this study was to analyze the description of patient safety culture at dr. Rasidin Hospital in 2018. This study used mixed method research design. The quantitative approach used AHRQ (Agency Health Research and Quality) 2004 questionnaire. The research subjects were 250 health workers who had direct contact with patient. A qualitative approach used in-depth interviews to find barriers on patient safety implementation. The result shows that the highest dimension of the positive response percentage was supervision dimension, $78 \%$, and the lowest dimension percentage of positive response is reporting frequency. The obstacles encountered in implementing a patient safety culture were the behavior of health workers and lack of support from management. For this reason the recommendations given were establishment of patient safety teams, education and evaluation monitoring.
\end{abstract}

Keywords: culture of patient safety, hospital, health employed

Affiliasi penulis: 1. Prodi S2 Kesehatan Masyarakat Fakultas Kedokteran Universitas Andalas Padang (FK Unand), 2. Bagian IImu Kesehatan Masyarakat-IImu Kesehatan Komunitas Fakultas Kedokteran Universitas Andalas Padang.

Korespondensi : Essy Mandriani, Email : essymandriani@yahoo.com Telp: 085296390303

\section{PENDAHULUAN}

Pada saat ini upaya untuk meningkatkan mutu pelayanan dan rneningkatkan upaya keselamatan pasien di rumah sakit sudah merupakan sebuah gerakan universal. Berbagai negara maju bahkan telah menggeser paradigma "quality" kearah paradigma baru Quality-safety yang mengandung arti tidak hanya 
meningkatkan mutu pelayanan, namun yang lebih penting adalah menjaga keselamatan pasien secara konsisten dan terus menerus. Keselamatan (safety) telah menjadi isu global termasuk juga untuk rumah sakit. Terdapat lima isu penting yang terkait dengan keselamatan (safety) di rumah sakit dan keselamatan pasien (patient safety) merupakan salah satunya. Kelima aspek keselamatan tersebut sangatlah penting untuk dilaksanakan disetiap rumah sakit. Namun harus diakui kegiatan institusi rumah sakit dapat berjalan apabila ada pasien, sehingga keselamatan pasien merupakan prioritas utama untuk dilaksanakan dan hal tersebut terkait dengan isu, mutu dan citra perumahsakitan. $^{1}$

Keselamatan pasien adalah suatu sistem yang membuat asuhan pasien lebih aman, meliputi asessmen risiko, identifikasi dan pengelolaan risiko pasien, pelaporan dan analisis insiden, kemampuan belajar dari insiden dan tindak lanjutnya, serta implementasi solusi untuk meminimalkan timbulnya risiko dan mencegah terjadinya cedera yang disebabkan oleh kesalahan akibat melaksanakan suatu tindakan atau tidak mengambil tindakan yang seharusnya diambil. Insiden keselamatan pasien adalah setiap kejadian yang tidak disengaja dan kondisi yang mengakibatkan atau berpotensi mengakibatkan cedera yang dapat dicegah pada pasien. $^{2}$

Rumah Sakit Umum Daerah (RSUD) dr Rasidin Padang merupakan salah satu institusi yang bertanggung jawab dalam memberikan pelayanan Kesehatan dengan mengutamakan penyembuhan dan pemulihan terhadap masyarakat Kota Padang. Rumah Sakit ini didirikan sejak tahun 1996 yang dulunya merupakan puskesmas plus dan berada dibawah naungan Puskesmas Belimbing Kecamatan Kuranji Padang. Pada Tahun 2002 RSUD ini diserahkan Dinas Kesehatan Kota Padang ke Pemerintah Daerah Kota Padang. Menurut Perda No.18/2002 RSUD ini merupakan lembaga teknis Daerah yang bertanggung jawab langsung kepada Pemerintah Daerah Kota Padang melalui Sekretaris Daerah Kota Padang. RSUD dr. Rasidin Padang merupakan rumah sakit tipe C (No.KARS SERT/661/VI/2012) yang merupakan rujukan bagi Puskesmas wilayah Kota Padang. Saat ini RSUD dr Rasidin Padang sedang dalam proses
Akreditasi yang mengacu pada SNARS (Standar Nasional Akreditasi Rumah Sakit). ${ }^{3}$

Berdasarkan hasil survei pendahuluan yang dilakukan oleh peneliti, pelaksanaan upaya kesalamatan pasien di RSUD dr Rasidin Padang ditemukan masalah seperti sasaran keselamatan pasien berupa komunikasi yang efektif, petugas kesehatan belum menggunakan sistem pencatatan perkembangan pasien terintegrasi. Pelaksanaan standard keselamatan pasien peningkatan keamanan obat yang perlu diwaspadai, fasilitas pemisahan obat yang berbahaya (high alert) dengan obat yang biasa masih belum memadai. Sasaran keselamatan pasien yaitu memastikan lokasi pembedahan dulunya sebelum operasi dokter melaksanakan penandaan dengan marker, namun saat ini hal tersebut tidak lagi dilaksanakan. Hasil observasi sasaran pengurangan resiko pasien jatuh, penilaian pasien resiko jatuh sudah dilakukan di IGD namun antrian untuk pasien resiko jatuh tidak dibedakan dengan pasien lainnya, hal ini menyebabkan masih terjadi insiden pasien jatuh.

Berdasarkan wawancara yang dilakukan pada kepala ruangan dari 10 ruangan 9 orang menjawab pernah ada insiden keselamatan pasien dalam satu tahun terakhir, baik itu insiden jatuh, dan pasien infeksi akibat pemasangan infus tetapi angka kejadiannya tidak diketahui secara pasti karena pelaporan yang kurang lengkap.

Saat ini Komite Keselamatan Pasien Rumah Sakit belum terbentuk. Standar Operasional Prosedur tentang keselamatan pasien sudah ada tetapi pelaksanaannya belum maksimal. Pencatatan dan pelaporan kejadian yang tidak diinginkan pada pasien tidak dilaksanakan, Berdasarkan wawancara dengan Kabid Keperawatan insiden keselamatan pasien masih ada ditemukan di lapangan, tetapi tidak dilaporkan oleh perawat.

Keselamatan pasien dipengaruhi oleh bagaimana budaya individu dan sistem yang berjalan di dalam organisasi tersebut. Sehingga harus dilakukan pendekatan secara personal/individu maupun sistem manajemen di dalam institusi tersebut. Budaya keselamatan di berbagai Industri berkembang sangat pesat. Angka kecelakaan kerja menurun karena didukung oleh kesadaran akan arti pentingnya 
nilai keselamatan dalam organisasi, namun dalam praktik kedokteran program keselamatan pasien baru dihembuskan secara luas setelah adanya paksaan dari luar. ${ }^{4}$

Sebuah penelitian mengungkapkan bahwa keberhasilan pelaksanaan program keselamatan pasien oleh petugas rumah sakit dipengaruhi oleh beberapa hal, salah satu nya adalah budaya keselamatan pasien. Saat ini sudah banyak penelitian mengenai budaya keselamatan pasien dan pengaruhnya terhadap pelaksaan program keselamatan pasien. ${ }^{5}$ Penelitian Nygren et al (2013) mengungkapkan bahwa budaya keselamatan pasien menjadi faktor pendukung dalam pelaksanaan program keselamatan pasien. Budaya keselamatan pasien akan memotivasi petugas untuk melaporkan setiap insiden keselamatan pasien yang terjadi. ${ }^{6}$

Dalam upaya meminimalisir terjadinya KTD yang terkait dengan aspek keselamatan pasien maka manajemen rumah sakit perlu menciptakan adanya budaya keselamatan pasien yang harus diterapkan dalam seluruh lingkup rumah sakit. AHRQ (Agency Health Research and Quality) mengemukakan budaya keselamatan pasien terdiri atas 12 dimensi. $^{8}$ Berdasarkan uraian diatas, penulis tertarik ingin menganalisis bagaimana budaya keselamatan pasien di RSUD dr Rasidin Padang. Hal inilah yang melatarbelakangi penulis untuk meneliti "Analisis Dimensi Budaya Keselamatan Pasien oleh Petugas Kesehatan di RSUD dr Rasidin Padang".

\section{METODE}

Penelitian ini menggunakan pendekatan mix method atau desain sequential explanatory yaitu metode penelitian yang menggabungkan kuantitatif dan kualitatif secara berurutan. Metode ini menggunakan metode kuantitatif pada tahap pertama, dan menggunakan metode kualitatif pada tahap kedua untuk mengumpulkan dan menganalisis data, guna memperkuat hasil penelitian kuantitatif yang dilakukan pada tahap pertama. $^{7}$

Penelitian dimulai dengan pengumpulan data dengan menggunakan kuesioner AHRQ (Agency Health Research and Quality) tahun 2004 yang berjudul Hospital Survey on Patient Safety Culture untuk mendeskripsikan budaya keselamatan pasien di
RSUD dr Rasidin Padang. ${ }^{8}$ Setelah itu, dilanjutkan dengan mengumpulkan dan menganalisis data yang didapatkan dari indept interview.

Cara pengambilan sampel adalah dengan menggunakan total population sampling, dimana seluruh anggota populasi yang memenuhi kriteria inklusi akan diambil sembagai sampel dalam penelitian ini, besarnya sampel adalah sebesar 250 orang. Analisis data kualitatif menggunakan metode thematic frameworks analysis.

\section{HASIL}

Persentase respon positif dari 12 dimensi budaya keselamatan pasien menunjukkan bahwa dimensi yang memiliki persentase respon positif tertinggi adalah dimensi supervisi yaitu sebesar $78 \%$, sedangkan dimensi dengan persentase respon positif terendah yaitu dimensi frekuensi pelaporan sebesar $31 \%$.

Data ini didukung oleh jawaban responden tentang pelaporan insiden keselamatan pasien selama 12 bulan terakhir yang dapat dilihat pada diagram berikut :

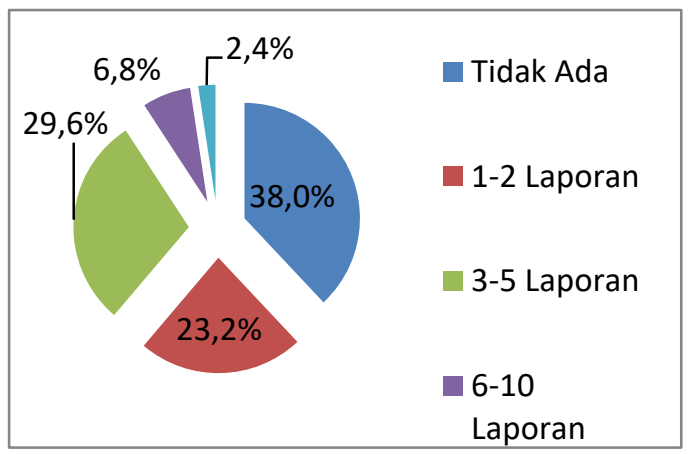

Gambar 1. Jawaban responden tentang pelaporan insiden

Berdasarkan diagram diatas dapat dilihat bahwa sebanyak $38 \%$ responden mengatakan bahwa selama 12 bulan terakhir tidak ada laporan insiden keselamatan pasien yang dilaporkan.

$\mathrm{Hal}$ ini menunjukkan bahwa budaya keselamatan pasien di RSUD dr Rasidin Padang masih belum terlaksana dengan maksimal yang disebabkan oleh beberapa hambatan yang ada. Maka dilakukanlah wawancara kepada beberapa informan.

Hasil rangkuman wawancara mendalam yang dilakukan kepada informan dapat dilihat pada Tabel 1. 
Tabel 1. Rangkuman hasil wawancara mendalam kepada informan

\begin{tabular}{|c|c|}
\hline Tema & Hasil \\
\hline $\begin{array}{l}\text { Program Keselamatan } \\
\text { Pasien }\end{array}$ & $\begin{array}{l}\text { Program Keselamatan di } \\
\text { RSUD dr Rasidin Padang } \\
\text { sudah tertuang dalam } \\
\text { Kebijakan seperti SK } \\
\text { Direktur dan SOP namun } \\
\text { pelaksanaannya belum } \\
\text { maksimal }\end{array}$ \\
\hline $\begin{array}{l}\text { Evaluasi Budaya } \\
\text { Keselamatan Pasien }\end{array}$ & $\begin{array}{l}\text { Evaluasi budaya } \\
\text { keselamatan pasien di } \\
\text { RSUD dr Rasidin padang } \\
\text { tidak pernah dilakukan }\end{array}$ \\
\hline $\begin{array}{l}\text { Pemahaman Petugas } \\
\text { tentang Budaya } \\
\text { Keselamatan Pasien }\end{array}$ & $\begin{array}{l}\text { Petugas sudah paham } \\
\text { tentang adanya budaya } \\
\text { keselamatan pasien namun } \\
\text { tidak didukung dengan } \\
\text { kelengkapan fasilitas, } \\
\text { selain itu tidak juga } \\
\text { membiasakan diri untuk } \\
\text { melaksanakan budaya } \\
\text { keselamatan pasien. }\end{array}$ \\
\hline $\begin{array}{l}\text { Laporan Insiden } \\
\text { Keselamatan Pasien }\end{array}$ & $\begin{array}{l}\text { Insiden keselamatan pasien } \\
\text { tidak dilaporkan dengan } \\
\text { baik, belum ada sistem } \\
\text { pelaporan yang baik di } \\
\text { RSUD dr Rasidin Padang }\end{array}$ \\
\hline $\begin{array}{l}\text { Hambatan Pelaksanaan } \\
\text { Budaya Keselamatan }\end{array}$ & $\begin{array}{lr}\text { Hambatan } & \text { dalam } \\
\text { pelaksanaan } & \text { Budaya }\end{array}$ \\
\hline Pasien & $\begin{array}{l}\text { Keselamatan pasien di } \\
\text { RSUD dr Rasidin Padang } \\
\text { tahun } 2018 \text { adalah Perilaku } \\
\text { dari petugas kesehatan dan } \\
\text { dukungan manajemen } \\
\text { dalam melengkapi fasilitas. }\end{array}$ \\
\hline
\end{tabular}

\section{PEMBAHASAN}

\section{Dimensi Persepsi}

Persepsi dari petugas kesehatan tentang budaya keselamatan pasien merupakan hasil dari proses kognitif yang selama ini diterapkan oleh petugas kesehatan dalam memberikan pelayanan kesehatan. Di RSUD dr Rasidin Padang dimensi persepsi ini adalah sebesar 57\% dengan kategori cukup. Hal ini menunjukkan bahwa selama ini tingkat pemahaman budaya keselamatan pasien dari petugas kesehatan sudah cukup, namun sebaiknya harus ditingkatkan lagi sehingga pelaksanaan program keselamatan pasien dilakukan secara maksimal.

Hasil penelitian Hall et al (2004) mengatakan bahwa rendahnya jumlah perawat professional dan berpengalaman yang bekerja pada sebuah unit semakin tinggi juga jumlah insiden medical error. Banyaknya proporsi perawat professional dan berpengalaman akan menghasilkan pemahaman dan persepsi pada program keselamatan pasien yang baik sehingga dapat mencegah terjadinya insiden keselamatan pasien. ${ }^{9}$

\section{Dimensi Frekuensi Pelaporan}

Hasil penelitian menunjukkan bahwa dimensi Frekuensi Pelaporan merupakan dimensi yang memiliki persentasi respon postif terendah yaitu sebesar 31\% dengan kategori kurang. Hal ini sejalan dengan jawaban dari responden sebanyak 95 orang (38\%) yang megungkapkan bahwa tidak ada jumlah kejadian yang dilaporkan dalam 12 bulan terakhir yang menunjukkan bahwa sistem pelaporan insiden di RSUD dr Rasidin Padang belum tertata dengan baik.

Menurut Najihah (2018) dengan melakukan pelaporan insiden keselamatan pasien dapat meningkatkan penerapan budaya keselamatan pasien sehingga insiden keselamatan pasien tersebut dapat dihindari. Namun masih banyak petugas kesehatan yang mengabaikan pelaporan insiden tersebut karena merasa insiden tersebut dapat ditangani sendiri dan hanya melaporkan apabila sudah terjadi cedera. ${ }^{10}$

\section{Dimensi Supervisi}

Setiap unit kerja memiliki kepala atau pimpinan yang bertugas melakukan supervisi terhadap bawahannya. Di RSUD dr Rasidin Padang dimensi supervisi memiliki nilai persentasi respon positif tertinggi yaitu sebesar $78 \%$ dengan kategori baik. Menurut penelitian Rakhmawati (2011) terdapat hubungan yang positif dari kepemimpinan transformasional dengan penerapan budaya keselamatan pasien. ${ }^{11}$ Kepemimpinan merupakan kemampuan untuk memperngaruhi orang lain dalam hal ini para bawahan sehingga mau dan mampu melakukan kegiatan tertentu meskipun secara pribadi hal tersebut mungkin tidak disenanginya. ${ }^{12}$ 


\section{Dimensi Pembelajaran Organisasi}

Dimensi pembelajaran organisasi termasuk dalam kategori cukup yaitu sebesar $61 \%$. Pembelajaran organisasi berkaitan dengan survey dan evaluasi dari kegiatan. Berdasarkan wawancara dengan beberapa informan diungkapkan bahwa sampai saat ini di RSUD dr Rasidin Padang tidak pernah dilaksanakan survey atau evaluasi tentang budaya keselamatan pasien. Kim berpendapat bahwa pembelajaran organisasi menekankan penggunaan proses belajar pada tingkat individu untuk mentranformasikan organisasi kedalam berbagai cara yang dapat meningkatkan kepuasan para stakeholder. Jika organisasi mempekerjakan orang-orang yang memiliki kompetensi dan pengetahuan tertentu yang diperoleh dari pekerjaan mereka maupun dari pendidikan formal maka organisasi akan mendapatkan manfaat dari berbagai aktifitas individu terdidik tersebut. $^{13}$

\section{Dimensi Kerjasama Intra Bagian}

Dimensi kerjasama intra bagian termasuk dalam kategori cukup yaitu sebesar 65\%. Hal ini menunjukkan bahwa dalam memberikan pelayanan kesehatan petugas kesehatan sudah menjalin kerjasama yang baik. Diharapkan hal ini dapat dtingkatkan agar kinerja masing-masing bagian dapat ditingkatkan juga.

\section{Dimensi Keterbukaan Informasi}

Dimensi Keterbukaan Informasi termasuk kategori cukup yaitu sebesar 62\%. Keterbukaan informasi merupakan kunci untuk melaksanakan kesehatan yang baik. Kesalahan komunikasi dapat mengakibatkan resiko insiden keselamatan pasien dapat meningkat. Komunikasi tidak terjadi antara petugas kesehatan dengan pasien saja, namun juga dengan sesame petugas kesehatan, baik yang medis maupun non medis. Menurut penelitian Kusumapradja pola komunikasi berpengaruh terhadap budaya keselamatan pasien. Pola komunikasi adalah menggambarkan saling percaya dan terbuka (communication founded on mutual trust and openness); Alur dan proses informasi yang baik (good information flow and processing) akan meningkatkan budaya keselamatan pasien. ${ }^{14}$

\section{Dimensi Timbal Balik Kesalahan}

Dimensi Timbal balik kesalahan termasuk dalam kategori cukup yaitu sebesar $66 \%$. Pelaksanaan timbal balik kesalahan di RSUD dr Rasidin Padang harus ditingkatkan lagi. Apabila terjadi suatu insiden maka harus cepat diberikan respon terhadap laporan tersebut, segera dicari kesalahannya dan dicari jalan keluarnya. Setelah itu dilakukan evaluasi dan dicari bagaimana cara pencegahan agar insiden tersebut tidak terulang kembali.

\section{Dimensi sangsi kesalahan}

Dimensi sangsi kesalahan di RSUD dr Rasidin Padang masuk dalam kategori kurang yaitu sebesar 43\%. Sangsi kesalahan berbeda dengan blaming culture yang artinya hanya menyalahkan orang yang melakukan kesalahan, namun artinya adalah menunjukkan sejauh mana tentang kesalahan pelayanan yang terjadi tidak ditanggapi dengan hukuman melainkan dengan identifikasi masalah yang terjadi dan mencari penyebabnya. Canadian Nurse Association menyatakan kesalahan medis sangat jarang disebabkan oleh factor kesalahan manusia secara tunggal, namun lebih banyak disebabkan karena kesalahan system di rumah sakit. ${ }^{15}$

Menurut Rachmawati (2011) faktor individu atau petugas sangat berpengaruh terhadap budaya keselamatan pasien adalah perasaan takut disalahkan. Adanya budaya menyalahkan di lingkungan rumah sakit menyebabkan petugas cenderung tidak melaporkan insiden keselamatan pasien karena takut dimarahi atau karena takut temannya dalam masalah. ${ }^{11}$

\section{Dimensi Staff}

Dimensi staff termasuk dalam kategori kurang yaitu sebesar $40 \%$. Hal tersebut mengintrepasikan bahwa petugas di rumah sakit masih kurang. Permasalahannya adalah kurangnya jumlah tenaga kerja sehingga menyebabkan jam kerja dari petugas kesehatan yang ada menjadi berlebih. Dapat dibuktikan dengan lebih banyaknya jumlah petugas kesehatan yang jam kerjanya $>40$ jam per minggu. Jam kerja yang melebihi batas juga dapat menyebabkan terpicunya stress. Kondisi stres seseorang ditentukan oleh keseimbangan antara 
tutuntutan yang ditujukan (seperti beban kerja) terhadap sumber daya yang dimiliki individu untuk mengatasi tuntutan tersebut (seperti pengalaman, keterampilan), ketika tuntutan yang diterima melebihi kemampuan yang dimiliki maka akan menimbulkan kondisi yang tidak menyenangkan seperti; kecemasan atau perasaan tidak sehat, kurang konsentrasi atau perasaan mudah marah.

\section{Dimensi Dukungan Manajemen}

Dimensi dukungan manajemen termasuk dalam kategori cukup yaitu sebesar 58\%. Seharusnya dimensi dukungan manajemen ini adalah baik, sebab terlaksananya program keselamatan pasien di RSUD dr Rasidin Padang tidak lepas dari dukungan manajemen. Berdasarkan wawancara dengan petugas kesehatan yang ada, dukungan manajemen dirasa masih kurang seperti untuk kelengkapan sarana dan kurangnya pelatihan untuk petugas dalam pelaksanaan kesalamatan pasien ini. Berbeda dengan hasil penelitian yang dilakukan oleh Nur Athifah et al (2014) yang menyatakan bahwa dimensi dukungan manajemen di di RSUD Syekh Yusuf Kabupaten Gowa termasuk dalam kategori baik yaitu sebesar $82,5 \%$. $^{16}$

\section{Dimensi Kerjasama Antar Bagian}

Dimensi kerjasama antar bagian termasuk dalam kategori cukup yaitu sebesar 52\%. Hal ini menunjukkan kekompakan petugas kesehatan untuk saling bekerjasama dan berkoordianasi dalam memberikan pelayan kesehatan sudah cukup.

\section{Dimensi Pemindahan dan Pergantian}

Dimensi Pemindahan dan pergantian termasuk dalam kategori cukup yaitu sebesar 62\%. Pada dimensi ini berkaitan dengan koordinasi dari petugas kesehatan pada saat pergantian shift kerja. Biasanya pada hal ini sering sekali terjadi kehilangan data dan informasi dari pasien. Begitu juga dengan kegiatan pemindahan pasien, harus dilakukan secara baik dan professional. Untuk itu RSUD dr Rasidin Padang perlu meningkatkan atau melakukan inovasi khusus pada kegiatan pemindahan dan pergantian. Sesuai dengan hasil penelitian oleh Starmer et al (2014) yang menyatakan bahwa kesalahan medis dapat menurun
$23 \%$ setelah dilakukan intervensi program Handoff (timbang terima), dan pelatihan komunikasi pada proses pemindahan dan pergantian. ${ }^{17}$

\section{Hambatan Terlaksananya Budaya Keselamatan Pasien}

Berdasarkan hasil wawancara dari informan dan data yang ada diperoleh hambatan dalam penerapan Budaya Keselamatan Pasien di RSUD dr Rasidin Padang adalah perilaku dan dukungan manajemen. Perilaku dapat diartikan sebagai suatu fungsi dari interaksi antara person atau individu dengan lingkungannya misalnya organisasi tempatnya bekerja. Thoha dalam bukunya menyatakan bahwa individu mempunyai karakteristik seperti kepercayaan diri, pengharapan kebutuhan dan pengalaman masa lalu nya. Begitu juga dengan organisasi yang merupakan suatu lingkungan juga memiliki karakteristik. Jika karekteristik individu dan karakteristik organisasi sudah berinteraksi maka terciptalah perilaku individu dalam organisasi. Perilaku seseorang itu ditentukan oleh banyak faktor. Adakalanya dipengaruhi oleh kemampuannya, kebutuhannya, dan dapat juga dipengaruhi oleh pengharapan dan lingkungannya. Oleh karena banyak faktor yang mempengaruhi perilaku tersebut, maka sering sekali organisasi kesulitan untuk menciptakan keadaan yang memimpin ke arah terciptanya efektivitas pelaksanaan kerja. $^{18}$

Penelitian Rachmawati mengemukakan bahwa faktor-faktor yang mempengaruhi budaya keselamatan pasien diantaranya ada di tingkat manajemen dan tingkat organisasi. Untuk tingkat manajemen meliputi persepsi manajemen tentang keselamatan pasien dan keterlibatan manajemen dalam keselamatan pasien. ${ }^{11}$ Hal ini menunjukkan bahwa apabila manajemen mendukung setiap petugas maka keselamatan pasien dapat dilaksanakan dengan baik.

\section{SIMPULAN}

Gambaran budaya keselamatan pasien menunjukkan hanya satu dimensi yang masuk kategori baik yaitu dimensi supervisi dengan persentase sebesar 78\%. Dimensi frekuensi pelaporan yang merupakan dimensi yang memiliki persentase respon positif terendah yaitu sebesar $31 \%$. Hambatan 
dalam pelaksanaan budaya keselamatan pasien ini terdiri dari perilaku dari petugas yang belum membiasakan diri untuk melaksanakan budaya keselamatan pasien dan juga dukungan manajemen dalam pelaksanaan budaya keselamatan pasien itu sendiri seperti respon untuk melengkapi fasilitas yang ada. Rekomendasi yang diberikan agar budaya keselamatan pasien dapat terlaksana dengan baik dengan adalah pembentukan Tim Keselamatan Pasien Rumah Sakit (KPRS), Edukasi, dan Monitoring secara berkala. Tim KPRS diharapkan dapat membuat program kerjanya berupa sistem pelaporan yang baik dan mudah dipahami oleh seluruh petugas.

\section{DAFTAR PUSTAKA}

1. Direktorat Jenderal Pelayanan Medik. Panduan nasional keselamatan pasien rumah sakit (patient safety). Jakarta: Departemen Kesehatan RI; 2008.

2. Kementerian Kesehatan RI. Peraturan Menteri Kesehatan Republik Indonesia No 11 Tahun 2017 tentang Keselamatan Pasien. Jakarta: Kementerian Kesehatan RI; 2017.

3. RSUD dr Rasidin Padang. Laporan tahunan RSUD dr Rasidin Padang. 2017.hlm.2.

4. Cahyono SB. Membangun budaya keselamatan pasien dalam praktek kedokteran. I. Jogjakarta: Kanisius; 2012.hlm.165.

5. Bardan RJ. Analisis penerapan keselamatan pasien di rumah sakit umum daerah Inche Abdoel Moeis tahun 2017 (tesis). Universitas Hasanuddin Makasar; 2017.hIm.11.

6. Nygren $M$, Roback $K$, Öhrn A, Rutberg $H$, Rahmqvist M, Nilsen P. Factors influencing patient safety in Sweden: Perceptions of patient safety officers in the county councils. BMC Health Serv Res. 2013;13(1):52.

7. Sugiyono. Metode Penelitian kuantitatif, kualitatif dan kombinasi (mixed method). Bandung: CV Alfabeta; 2015.hlm.54.

8. Sorra J, Gray L, Streagle S, et al. AHRQ hospital survey on patient safety culture: user's guide.
AHRQ Publication No. 15-0049-EF (Replaces 040041). Rockville, MD: Agency for healthcare research and quality 2016 (diakses 28 Maret 2018). Tersedia dari: http://www.ahrq.gov/ professionals/qualitypatientsafety/patientsafetycult ure/hospital/index.html

9. Hall LM, Doran, D, Pink GH. Nurse staffing models, nursing hours and patient safety outcomes. J Nurs Adm. 2004;34(1):41-5.

10. Najihah. Budaya keselamatan pasien dan insiden keselamatan pasien di rumah sakit: literature review. Journal of Islamic Nursing.2018;3(1):1-8.

11. Rachmawati E. Model pengukuran budaya keselamatan pasien di RS Muhammadiyah'Aisyiyah tahun 2011. Pros Penelit Bid IImu Eksakta. 2011;11-34.

12. Namawi I. Budaya organisasi kepemimpinan \& kinerja. Jakarta: Kencana Prenamedia Group; 2013.hlm.153.

13. Absah Y. Pembelajaran organisasi: strategi membangun kekuatan perguruan tinggi. Jurnal Manajemen Bisnis. 2008;1(1):33-41.

14. Kusumapradja R. Analisis budaya keselamatan pasien di rumah sakit daerah khusus ibu kota Jakarta. Forum IIm. 2017;14(2):211-29.

15. Canadian Nurses Association. University of Toronto faculty of nursing. nurses and patient safety: a discussion paper. Kanada: Canadian Nurses Association; 2004;(January):25.

16. Athifah N, Pasinringi SA, Kapalawi I. Gambaran budaya keselamatan pasien di RSUD Syekh Yusuf Kabuoaten Gowa. Repos Unhas. 2014;1-16. (diunduh tanggal 14 Mei 2018). Tersedia dari: http://repository.unhas.ac.id

17. Starmer AJ, Spector ND, Srivastava R, West DC, Rosenbluth G, Allen AD, et al. Changes in medical errors after implementation of a Hand off program. N Engl J Med. 2014;371(19):1803-12.

18. Thoha M. Perilaku organisasi: konsep dasar dan aplikasinya. Jakarta: PT Raja Grafindo Persada; 2009.hlm.167. 